\title{
Shaping Force and Torque Values during Canal Shaping using XP Shaper and OneCurve Systems
}

\author{
Ahmed Jamleh ( $\nabla$ aojamleh@gmail.com ) \\ King Saud bin Abdulaziz University for Health Sciences https://orcid.org/0000-0001-9504-2921 \\ Abdulmohsen Alfadley \\ King Saud bin Abdulaziz University for Health Sciences \\ Nasser Alghofaili \\ King Saud bin Abdulaziz University for Health Sciences \\ Hani Jamleh \\ Jordan university \\ Khalid Alfouzan \\ King Saud bin Abdulaziz University for Health Sciences
}

\section{Research article}

Keywords: Canal shaping; OneCurve; Shaping force; Torque; XP Shaper

Posted Date: August 23rd, 2019

DOI: https://doi.org/10.21203/rs.2.13494/v1

License: (9) (i) This work is licensed under a Creative Commons Attribution 4.0 International License. Read Full License 


\section{Abstract}

Background The aim of this in vitro study was to evaluate the magnitude of shaping forces and dynamic torques developed with XP shaper (XPS) and OneCurve (OC) systems during canal shaping of extracted teeth.Methods Thirty-two single-canalled mandibular premolars were divided into two groups: XPS and OC ( $\mathrm{n}=16$ each). In XPS and OC, the canals were shaped with their dedicated file inserted three times until it reached the canal length. The experiment was performed while the test sample was surrounded by water under controlled simulated intracanal temperature. The real-time shaping forces and torques induced during canal shaping were observed. The inward and outward peak shaping forces and the peak torques were recorded and used for statistical analysis by using the Mann-Whitney test. The statistical significance was set at $5 \%$.

Results In both groups, the developed shaping forces in both directions and the torques increased with the successive file insertions. The inward and outward peak forces of the XPS and OC groups ranged from 0.33 to $3.12 \mathrm{~N}$ and from 0.09 to 1.96 $\mathrm{N}$, respectively. The peak torque developed in both groups ranged from 0.12 to $1.52 \mathrm{~N} . \mathrm{cm}$. In the three insertions, the XPS showed significantly lower peak forces in both directions $(P=0.00)$. For the peak torque, XPS had significantly lower values in all the insertions $(P=0.00)$.Conclusions The XPS system had significantly lower shaping forces and lower dynamic torque values during canal shaping compared with the OC system.

\section{Background}

Thorough chemo-mechanical debridement of the complex root canal system is paramount to the success of endodontic therapy. While chemical cleaning aims to remove all organic substances including pulpal tissues, microbial biofilms, and toxic byproducts, the mechanical shaping should be performed to develop a continuously tapering canal that allows for optimal delivery of irrigating solutions and intracanal medicaments as well as three-dimensional obturation of the root canal system. Historically, stainless steel (SS) files were used to perform canal shaping during nonsurgical root canal treatment. Nowadays, nickel-titanium ( $\mathrm{NiTi}$ ) rotary files are widely used to shape the root canals owing to their increased flexibility, rapid and centered canal preparation, safer preparation of curved canals, improved cutting efficiency, superior torsional resistance, and improved treatment outcome $(1,2)$. In spite of all these advantages, a main limitation of the use of NiTi files is the risk of intracanal file fracture as a result of fatigue. Fatigue might be caused by cyclic fatigue and/or torsional fatigue. Cyclic fatigue develops when the file rotates in a curvature, producing alternating cycles of compression and tension until fracture occurs. Torsional fatigue occurs when the torque from contact between the file and root canal wall exceeds the file's torsional strength $(1,3)$.

Single-file systems have been introduced to simplify shaping procedure, reduce mechanical stress and shape the canal more quickly compared with multi-file systems (4). Therefore, various manufacturers have started to produce single-file systems. Contemporary advancements in NiTi files' production contributed to increased safety and efficiency of canal shaping. They include changes in the design, alloy treatments, and motion kinematics of NiTi files (5). These advancements played a key role in the evolvement of single NiTi systems, wherein the canal shaping is completed using one file. Studies have shown that single-file systems did not compromise canal cleanliness, compared with the conventional multi-file systems $(4,6)$. Furthermore, the use of single NiTi file is considered advantageous as it reduces cost, shaping time and risk of crosscontamination (7).

The use of rotary file systems was reported to induce less shaping force but more torque than the manual SS files (8). Past studies revealed that the force and torque exerted on the tooth during canal shaping directly affect the file fatigue (9-12) as well as the root canal wall (13). It has been shown that shaping force and torque are directly proportional (9). The low shaping force is, the reduced torque and the more extended file's lifetime will result in. These parameters are known to be influenced by many factors such as the motion kinematics, contact area between the file and the canal walls, file geometry and preoperative canal volume $(5,10-12)$.

XP Shaper (XPS; FKG Dentaire SA, La Chaux-de-fonds, Switzerland) is a single file system that is made with MaxWire technology (14). The file has an apical diameter of $0.30 \mathrm{~mm}$ and a fixed taper of $1 \%$. It has a triangular cross-section, six-blade tip and booster tip that allow to start shaping the canal after a manual glide path of at least size 15 . Upon exposure to body

Page $2 / 9$ 
temperature $\left(35^{\circ} \mathrm{C}\right)$, the martensite phase of the file converts to the austenite phase, and this let the file shape the canal to a taper of $4 \%$ because of a "snake" shape (14-16). OneCurve file (OC; Micromega, Besancon, France) is a rotary system that is used in continuous rotation to shape the canal completely with a single file. It is an evolution of OneShape system having the same variable cross section along the file, but it is made from heat-treated NiTi alloy (C. Wire) (17). The different manufacturing process have shown improved mechanical properties of the OC file (18).

Several experiments and protocols have been proposed to study the forces and torques generated during canal shaping with different rotary systems $(10-12,19-25)$. To the best of our knowledge, no study has evaluated the force and torque developed using XPS system. Hence, this in vitro study was conducted to determine the magnitude of shaping forces and torque values generated during the canal shaping using the XPS and compare them with that developed with the OC. The null hypothesis is that there would be no difference between the XPS and OC systems in terms of shaping force and torque during canal shaping.

\section{Methods}

\section{Teeth Selection}

Mandibular premolars were taken from a pool of extracted human teeth. Facial and proximal views were taken with a digital radiograph to select teeth with mature roots, narrow canals and a curvature of less than 10 degrees.

\section{Mounting of Teeth}

The tooth apex was covered with wax to avoid penetration of resin into the root canal, and the whole root was embedded in a mixed acrylic resin (DuraLay; Reliance Dental Mfg Co, Worth, IL). After the resin was set, the teeth were decoronated to a level that kept 15-mm root length to standardize the samples. The periodontal ligament was not simulated in this study in order to investigate pure forces on the internal root canal wall caused by the tested file systems [9].

The canal length (CL) was determined as $1 \mathrm{~mm}$ short of the apical foramen $(14 \mathrm{~mm})$. The narrow root canal was verified by placing a size $15 \mathrm{~K}$-file (Dentsply Sirona) that would bind no less than $3 \mathrm{~mm}$ from the CL. Otherwise, the tooth was excluded. According to these criteria, 32 root canals were selected for this study.

\section{Shaping Force and Torque Measurements}

A force gauge (M5-20 Advanced Digital Force Gauge; Mark-10 Corporation, Long Island, NY) with a force capacity for $100 \mathrm{~N}$ and torque gauge (TT01 torque Gauge; Mark-10 Corporation, Long Island, NY) with a torque capacity for 115 N.cm were used in this experiment.

The force gauge device was secured by the 4 pins of the torque gauge device in a standing position. Afterwards, the tooth assembly was firmly set on a fixed stage at the top of the force gauge so that the tooth was exactly centered to ensure axial measurements. The tooth assembly was surrounded with water inside a small tank under controlled simulated body temperature $\left(35 \pm 1^{\circ} \mathrm{C}\right)$, as confirmed by a thermocouple device (Figure 1$)$.

The shaping forces in 2 directions (inward and outward forces) and the generated torques were simultaneously measured and presented separately on two personal computers using MESUR ${ }^{\text {TM }}$ Lite software (Mark-10 Corporation, NY, USA). The inward force represented the force required to introduce the file into the canal, and the outward force represented the force developed when the file was pulled from the canal. The positive torque was measured.

\section{Root Canal Shaping}

After the establishment of a manual glide path with size $15 \mathrm{~K}$-file, the root canals were randomly assigned to 2 experimental groups ( $n=16)$ according to the NiTi system used for canal shaping; XPS and OC systems. 
In a pilot study, the measured torques of the tested files during shaping narrow canals did not exceed $2.5 \mathrm{~N} . \mathrm{cm}$. This made the use of X-Smart Plus (Dentsply Sirona) in both groups possible with the torque set at the upper limit (4 N.cm).

Before the canal shaping, the canal was filled with $1 \%$ sodium hypochlorite, and the force and torque gauges were zeroed. The XPS file was inserted three times until reaching the CL. The file in each insertion was gently used at a speed of 800 rotations per minute (rpm). The OC file size $258 \%$ taper was introduced into the canal three times at a speed of $300 \mathrm{rpm}$ until it reached the $\mathrm{CL}$.

After each file insertion, the file's flutes were cleaned with a gauze, canal patency was confirmed with a size $10 \mathrm{~K}$-file, and the root canal was irrigated with a $1 \% \mathrm{NaOCl}$. Each file was used to shape four canals or until evidence of deformation or fracture was noted. The canals from both groups were shaped alternately and gently with a single operator who had training on using the experimental systems. There was a stand at what the operator's hand was placed to be above the upper level of the root. With this, the canal shaping was performed with a controlled "in-out" movement.

The shaping time, which included the total active instrumentation, irrigation, recapitulation and file change, was recorded. Shaping force and torque data were expressed in Newtons $(\mathrm{N})$ and N.cm, respectively. The gauge devices measured data every 0.1 second.

\section{Data Analysis}

Differences between the mean inward and outward forces and peak torque values of the three shaping insertions in the two systems were tested for statistical significance using Mann-Whitney U-tests. The shaping times were analyzed using Student's t-test. The significance level was set at $5 \%$.

\section{Results}

Table 1 shows the descriptive data of axial inward and outward shaping peak forces and peak torque for each system.

The shaping forces in both directions and the torques increased with the successive file insertions. The inward and outward peak forces of the XPS and OC groups ranged from 0.33 to $3.12 \mathrm{~N}$ and from 0.09 to $1.96 \mathrm{~N}$, respectively. In the three insertions, the XPS showed significantly lower peak forces in both directions $(P=0.00)$.

The peak torque developed in both groups ranged from 0.12 to $1.52 \mathrm{~N} . \mathrm{cm}$. XPS had significantly lower torque values in all the insertions $(P=0.00)$.

The XPS and OC shaped the canals completely in 33.4 and 32.8 seconds $(P=0.7)$. No file fracture nor deformation has taken place throughout the experiment.

\section{Discussion}

This lab-based study was conducted to investigate the performance of two single file systems (XPS and OC) in terms of shaping force and torque induced during the shaping of narrow canals. It is notable that the shaping forces and peak torques created by the XPS file in the three insertions were lower than that induced with OC file and this led to rejection of the null hypothesis. The differences might be attributed to the alloy treatment, rotational speed, file design and file-wall contact (11, 21, 25). The XPS file is made of MaxWire alloy which makes it react in a favorable way to changes in temperature; once placed in the root canal, the file will appear as a snake that can accomm0odate the canal anatomy. Thus, the experiment was conducted under simulated intracanal temperature to follow the XPS manufacturer's instructions and to make the study more clinically relevant.

A previous study showed that rotating the file at higher speed generates less force and torque (21), which is consistent with our results since the XPS system rotates at higher speed than the OC system (800rpm Vs. 300rpm). Furthermore, the XPS file design presents a triangular cross section with size 30 and 1\% taper compared with the larger taper of the OC file. The OC file 
has \#30 tip size with 8\% constant taper. Its cross-section varies from a triangular-shaped at the file tip to S-shaped near the shaft. The manufacturer claims that this variable cross-section can respond to the need of efficient shaping while respecting the initial root canal anatomy (17). Although the XPS file taper is .01, the XPS file's "snake" shape can prepare the canal in 3 dimensions to achieve a final apical preparation of size 30 and $6 \% \pm 2 \%$ taper in the apical and middle thirds (16). And this preparation is considered larger than what $\mathrm{OC}$ file can create.

The current results show that XPS generated low forces and torques. The limited contact area between the XPS file and the root canal walls make it a promising design to shape the canal gently with less impact on the canal walls and on the file itself. The need for 3D canal shaping and the emphasis placed on less invasive treatments have increased in recent years. Proper and safe cleaning and shaping of root canals depend on the mechanical behavior of endodontic files (26). In a clinical setting, it has been shown the higher the shaping force is, the more torque will be generated that will create excessive stress on the file, followed by deformation and possible fracture $(22,27)$. Furthermore, these shaping procedures create higher stresses on the file. The shaping force directly influences the file's cyclic and torsional fatigue, which might result in file fracture $(9,12)$. Moving the file deeper into the root canal requires higher forces $(19,25)$ and this will generate more torque resulting in the file locking at or near the its tip (28). Dane et al (13) investigated the effect of torque on the root canal wall and found that canal shaping at high-torque setting induced more dentinal cracks than at low-torque settings. On the other hand, the resultant force and torque induce strain on the wall of the root canal, leading to the development of dentinal defects (29-31). Therefore, gentle shaping with low stress is required (22).

It is reported that shaping narrow canal with only one file without pre-shaping with smaller files generates a large contact surface with the dentin walls, resulting in high stresses on the file as well as the root canal walls (29). In a previous study, the WaveOne and WaveOne Gold single file systems generated a force that exceeded $6.4 \mathrm{~N}$ (25). However, the XPS, as a single file system, did not exceed $0.9 \mathrm{~N}$ force which is much lower than the shaping peak force induced by any tested multi-file system in the literature (10-12, 19-23). Moreover, the manufacturers of XPS and OC recommend setting the torque at $1 \mathrm{~N} . \mathrm{cm}$ and 2.5 N.cm, respectively, to avoid file fracture $(14,17)$. This experiment showed that the mean peak torque achieved in shaping narrow canal with XPS and OC did not exceed $0.5 \mathrm{~N} . \mathrm{cm}$ and $1.5 \mathrm{~N} . \mathrm{cm}$, respectively. This means that the shaping procedure remained well within the safety torque values of the files and can be used to shape at least four narrow canals using the shaping technique described in this experiment.

It is noteworthy that in this experiment no file fracture or deformation was observed in both groups.

The outward forces were tested to measure the "screwing-in" effect of the tested files (32). This effect is considered unfavorable since it might cause over-instrumentation because of the unwanted file penetration beyond the apex (30). The XPS induced favorably almost less than one third the outward force induced with OC in each insertion. For having the $1 \%$ taper, the XPS design (snake shape) limits the engagement of the file inside the canal to one or two points of contact at any given cross-section, which will, in turn, reduce the "screwing-in" effect.

Recently, the XPS file has been investigated in many aspects that showed improved cyclic fatigue, reduced debris extrusion, less instrumentation time, better canal cleanliness, and no formation of dentinal defect, compared to other commercially available file systems $(15,33-35)$. The present results add another benefit of the low shaping force and torque required to shape a root canal using XPS system. Given that shaping a canal with XPS can result in a canal with \#30 size and $6 \% \pm 2 \%$ taper with only a single file, this might show a proven effectiveness for shaping a canal with it.

The results of this study must be taken with caution since there are limitations that must be considered. The axial force and torque may be influenced by the operator, tooth position and root canal dimensions. Efforts were strictly undertaken to limit any variable that might appear in the experimental setup and to maintain a consistent and gentle pressure on the files. Thus, the selected canals were identified as narrow canals with standardized lengths. They were shaped by only one operator who is trained to use the tested systems. Furthermore, each tooth was placed centered on a fixed stage on the top of the force gauge and in a standing position simulating a position of a mandibular tooth to measure the pure force and torque developed along the long axis of the tooth. The canals from both groups were alternately shaped to avoid operator bias. Besides that, a stand 
was provided at what the operator's hand was placed to be above the upper level of the root. Future studies are needed to assess these parameters in detail.

\section{Conclusions}

In short, the two systems shaped the canals with different shaping forces and torques. The XPS system imposed lower shaping forces and torques compared with the OC system.

\section{Abbreviations}

XPS: XP shaper; OC: OneCurve; SS: Stainless steel; NiTi: Nickel-titanium; CL: Canal length

\section{Declarations}

\section{Ethics approval and consent to participate}

This work was ethically approved by King Abdullah International Medical Research Center, Ministry of National Guard Health Affairs, Riyadh, Saudi Arabia.

\section{Consent to publish}

Not applicable

\section{Availability of data and materials}

The datasets used and/or analyzed during the current study are available from the corresponding author on reasonable request.

\section{Competing interests}

The authors declare that they have no competing interests

\section{Funding}

This work was supported by King Abdullah International Medical Research Center (RC18/187/R).

\section{Authors' Contributions}

AJ and AA designed the experiment. AJ, AA and NA participated in conducting the experiment. AJ analyzed the data statistically. AJ, AA, NA, HJ and KA wrote and edited the manuscript. The authors read and approved the final manuscript.

\section{Acknowledgement}

The authors deny any conflict of interest

\section{References}

1-Glosson C, Haller R, Dove S, del Rio C. A comparison of root canal preparations using Ni-Ti hand, Ni-Ti engine- driven and KFlex endodontic instruments. J Endod 1995;21:146-51.

2-Cheung G, Liu C. A retrospective study of endodontic treatment outcome between nickel-titanium rotary and stainless steel hand filing techniques. J Endod 2009;35:938-43.

3-Jamleh A, Sadr A, Nomura $\mathrm{N}$ et al. Nano-indentation testing of new and fractured nickel-titanium endodontic instruments. Int Endod J 2012;45:462-8. 
4-Bürklein S, Benten S, Schafer E. Shaping ability of different single-file systems in severely curved root canals of extracted teeth. Int Endod J 2013;46:590-7.

5-Capar ID, Arslan H. A review of instrumentation kinematics of engine-driven nickel-titanium instruments. Int Endod J 2016;49:119-35.

6-Capar ID, Ertas H, Ok E, Arslan H, Ertas E. Comparative study of different novel nickel-titanium rotary systems for root canal preparation in severly curved root canals. J Endod 2014;40:852-6.

7-Yared G. Canal preparation using only one Ni-Ti rotary instrument: preliminary observations. Int Endod J 2008;41:339-44.

8-Bürklein S, Stüber J, Schäfer E. Real-time dynamic torque values and axial forces during preparation of straight root canals using three different endodontic motors and hand preparation. Int Endod J 2019;52:94-104.

9-Gambarini G. Cyclic fatigue of ProFile rotary instruments after prolonged clinical use. Int Endod J 2001;34:386-9.

10-Peters OA, Peters Cl, Schonenberger K, Barbakow F. ProTaper rotary root canal preparation: assessment of torque and force in relation to canal anatomy, Int Endod J 2003;36:93-9.

11-Da Silva FM, Kobayashi C, Suda H. Analysis of forces developed during mechanical preparation of extracted teeth using RaCe rotary instruments and ProFiles. Int Endod J 2005;38:17-21.

12-Schrader $\mathrm{C}$, Peters $\mathrm{O}$. Analysis of torque and force during step-back with differently tapered rotary endodontic instruments in vitro. J Endod 2005;31:120-3.

13-Dane A, Capar ID, Arslan H, Akçay M, Uysal B. Effect of Different Torque Settings on Crack Formation in Root Dentin. J Endod 2016;42:304-6.

14-FKG Dentaire SA. XP-Endo shaper: the one to shape your success. Available at:

http://www.fkg.ch/sites/default/files/201704_fkg_xp_endo_shaper_brochure_v4_en_web.pdf. Accessed May 10, 2019.

15-Bayram HM, Bayram E, Ocak M, et al. Effect of ProTaper Gold, Self-Adjusting File, and XP-endo Shaper instruments on dentinal microcrack formation: a micro- computed tomographic study. J Endod 2017;43:1166-9.

16- Azim A, Piasecki L, da Silva Neto U, Cruz A, Azim K. XP Shaper, A Novel Adaptive Core Rotary Instrument: Micro-computed Tomographic Analysis of Its Shaping Abilities. J Endod. 2017;43:1532-8

17-One Curve - MICRO-MEGA. Available from: https://micro-mega.com/shaping/one-curve?lang=en. Accessed May 10, 2019.

18-Serafin M, De Biasi M, Franco V, Angerame D. In vitro comparison of cyclic fatigue resistance of two rotary single-file endodontic systems: OneCurve versus OneShape. Odontology. 2019;107:196-201.

19-Peters OA, Barbakow F. Dynamic torque and apical forces of ProFile .04 rotary instruments during preparation of curved canals. Int Endod J 2002;35:379-89.

20-Diop A, Maurel N, Oiknine M, et al. A novel platform for in vitro analysis of torque, forces, and three-dimensional file displacements during root canal preparations: application to ProTaper rotary files. J Endod 2009;35:568-72.

21-Bardsley S Peters C, Peters 0 . The effect of three rotational speed settings on torque and apical force with vortex rotary instruments in vitro. J Endod 2011;37:860-4.

22-Glavic `ic' S, Anic' I, Braut A, Miletic' I, Borc `ic' J. Vertical force and torque analysis during mechanical preparation of extracted teeth using hand ProTaper instruments. Aust Endod J 2011;37:51-5. 
23-Jamleh A, Alfouzan K. Vertical load induced with Twisted File Adaptive System during canal shaping. J Endod 2016;42:1811-4.

24-Kwak SW, Ha JH, Cheung GS, Kim HC, Kim SK. Effect of the glide path establishment on the torque generation to the files during instrumentation: an in vitro measurement. J Endod 2018;44:496-500.

25-Jamleh A, Alfadley A, Alfouzan K. Vertical Force Induced with WaveOne and WaveOne Gold Systems during Canal Shaping. J Endod 2018;44:1412-5.

26-Lopes HP, Elias CN, Vieira MV, et al. Fatigue life of Reciproc and Mtwo instruments subjected to static and dynamic tests. J Endod 2013;39:693-6.

27-Gambarini G. Rationale for the use of low-torque endodontic motors in root canal instrumentation. Endod Dent Traumatol 2000;16:95-100.

28-Nalla RK, Kinney JH, Ritchie RO. On the fracture of human dentin: is it stress- or strain-controlled? J Biomed Mater Res 2003;67:484-95.

29-Jamleh A, Komabayashi T, Ebihara A et al. Root surface strain during canal shaping and its influence on apical microcrack development: a preliminary investigation. Int Endod J 2015;48:1103-11.

30-Adorno CG, Yoshioka T, Suda H. Crack initiation on the apical root surface caused by three different nickel-titanium rotary files at different working lengths. J Endod 2011;37:522-5.

31-Jamleh A, Adorno CG, Ebihara A, Suda H. Effect of nickel titanium file design on the root surface strain and apical microcracks. Aust Endod J 2016;42:25-31.

32-Ha JH, Cheung GS, Versluis A, et al. 'Screw-in' tendency of rotary nickel-titanium files due to design geometry. Int Endod J 2015;48:666-72.

33-Lacerda M, Marceliano-Alves M, Pérez A et al. Cleaning and Shaping Oval Canals with 3 Instrumentation Systems: A Correlative Micro-computed Tomographic and Histologic Study. J Endod 2017;43:1878-84

34-Keskin C, Inan U, Guler DH, Kalyoncuoğlu E. Cyclic Fatigue Resistance of XP-Endo Shaper, K3XF, and ProTaper Gold Nickeltitanium Instruments. J Endod 2018;44:1164-7.

35- Uslu G, Özyürek T, Yılmaz K, Gündoğar M, Plotino G. Apically Extruded Debris during Root Canal Instrumentation with Reciproc Blue, HyFlex EDM, and XP-endo Shaper Nickel-titanium Files. J Endod 2018;44:856-9

\section{Tables}

Table 1. Descriptive data (Mean \pm standard deviation) of shaping time and peak values of shaping force and torque for each insertion in the tested systems.

\begin{tabular}{|c|c|c|c|c|c|c|c|c|c|c|}
\hline \multirow[t]{3}{*}{ Group } & \multicolumn{6}{|c|}{ Shaping force $(\mathrm{N})$} & \multicolumn{3}{|c|}{ Maximum torque (N.cm) } & \multirow{3}{*}{$\begin{array}{l}\text { Shaping } \\
\text { time (s) }\end{array}$} \\
\hline & \multicolumn{2}{|c|}{ First insertion } & \multicolumn{2}{|c|}{ Second insertion } & \multicolumn{2}{|c|}{ Third insertion } & \multirow{2}{*}{$\begin{array}{c}\text { First } \\
\text { insertion }\end{array}$} & \multirow{2}{*}{$\begin{array}{c}\text { Second } \\
\text { insertion }\end{array}$} & \multirow{2}{*}{$\begin{array}{c}\text { Third } \\
\text { insertion }\end{array}$} & \\
\hline & $\begin{array}{l}\text { Inward } \\
\text { force }\end{array}$ & $\begin{array}{l}\text { Outward } \\
\text { force }\end{array}$ & $\begin{array}{l}\text { Inward } \\
\text { force }\end{array}$ & $\begin{array}{l}\text { Outward } \\
\text { force }\end{array}$ & $\begin{array}{l}\text { Inward } \\
\text { force }\end{array}$ & $\begin{array}{l}\text { Outward } \\
\text { force }\end{array}$ & & & & \\
\hline $\begin{array}{c}\text { XPS } \\
(n=16)\end{array}$ & $0.33 \pm 0.23$ & $0.09 \pm 0.21$ & $0.45 \pm 0.37$ & $0.44 \pm 0.35$ & $0.89 \pm 0.48$ & $0.76 \pm 0.38$ & $0.12 \pm 0.11$ & $0.24 \pm 0.17$ & $0.46 \pm 0.19$ & $33.42 \pm 3.35$ \\
\hline $\begin{array}{c}\text { OC } \\
(n=16)\end{array}$ & $1.50 \pm 0.57$ & $1.16 \pm 0.43$ & $2.03 \pm 0.74$ & $1.56 \pm 0.53$ & $3.12 \pm .91$ & $1.96 \pm 0.82$ & $0.61 \pm 0.26$ & $0.89 \pm 0.34$ & $1.52 \pm 0.48$ & $32.84 \pm 4.84$ \\
\hline $\begin{array}{c}\mathrm{P}- \\
\text { value }\end{array}$ & 0 & 0 & 0 & 0 & 0 & 0 & 0 & 0 & 0 & 0.7 \\
\hline
\end{tabular}


Figures

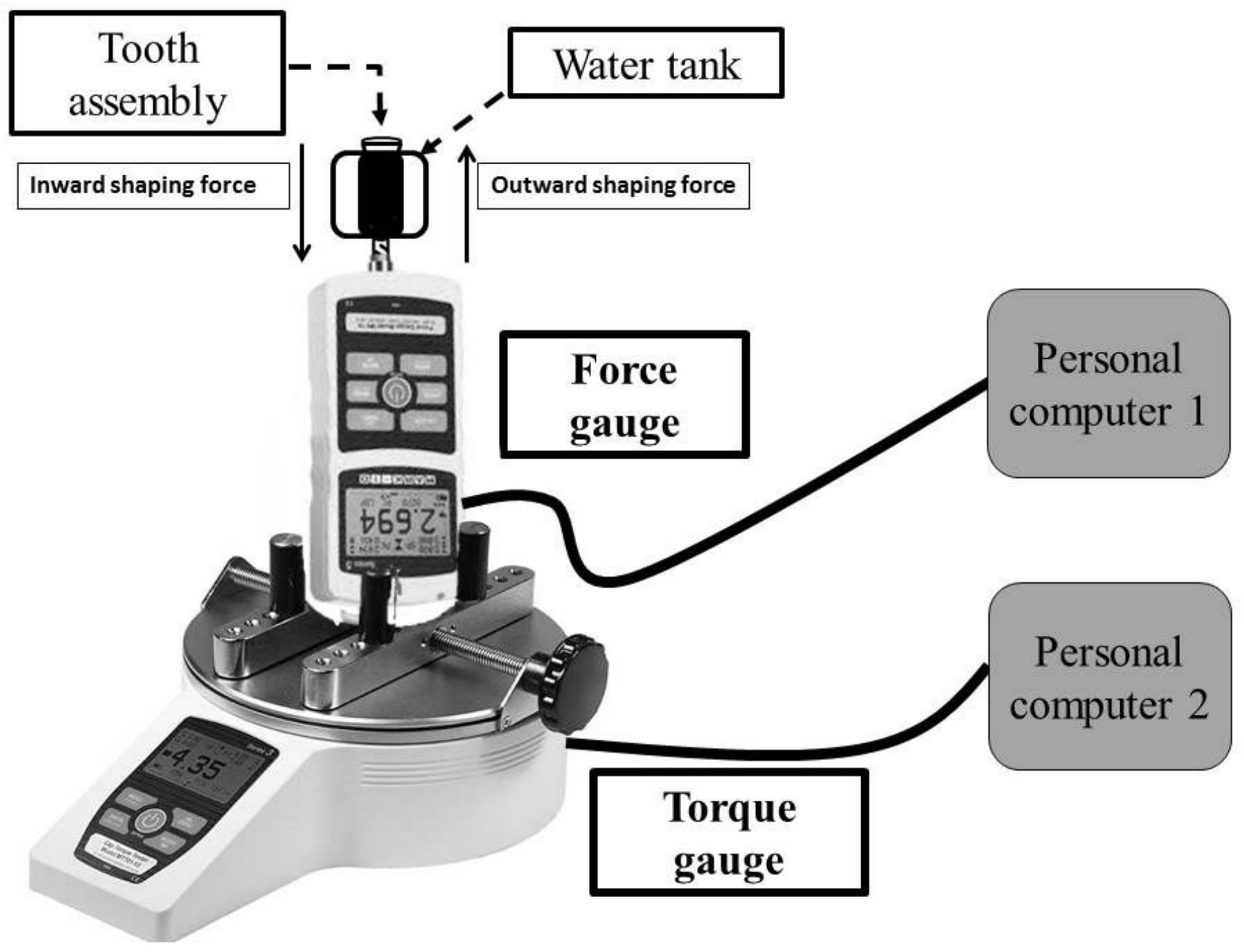

Figure 1

Schematic drawing of the experimental set-up. The force gauge and torque gauge devices (Mark-10 Corporation) were used for recording shaping forces and torques, respectively. The data are presented separately on two separate PCs using MESUR Lite software (Mark-10 Corporation). 